\title{
A heat-inactivated H7N3 vaccine induces cross-reactive cellular immunity in HLA-A2.1 transgenic mice
}

\author{
Giuseppina Di Mario ${ }^{1 \dagger}$, Bruno Garulli ${ }^{2 \dagger}$, Ester Sciaraffia $^{1}$, Marzia Facchini ${ }^{1}$, Isabella Donatelli ${ }^{1}$ and Maria R. Castrucci ${ }^{1 *}$
}

\begin{abstract}
Background: Cross-reactive immunity against heterologous strains of influenza virus has the potential to provide partial protection in individuals that lack the proper neutralizing antibodies. In particular, the boosting of memory CD8+ T cell responses to conserved viral proteins can attenuate disease severity caused by influenza virus antigenic variants or pandemic strains. However, little is yet known about which of these conserved internal antigens would better induce and/or recall memory CD8+ T cells after in vivo administration of an inactivated whole virus vaccine.

Methods: We explored the CD8 + T cell responses to selected epitopes of the internal proteins of an $\mathrm{H} 7 \mathrm{~N} 3$ influenza virus that were cross-reactive with A/PR/8/34 virus in HLA-A2.1 transgenic (AAD) mice.

Results: CD8+ T cells against dominant and subdominant epitopes were detected upon infection of mice with live H7N3 virus, whereas immunization with non-replicating virus elicited CD8+ T cell responses against mostly immunodominant epitopes, which were rapidly recalled following infection with A/PR/8/34 virus. These vaccine-induced $T$ cell responses were able to reduce the lung viral load in mice challenged intranasally with the heterologous influenza virus.
\end{abstract}

Conclusions: A single immunization with non-replicating influenza virus vaccines may be able to elicit or recall cross-reactive CD8+ T cell responses to conserved immunodominant epitopes and, to some extent, counteract an infection by heterologous virus.

\section{Background}

Influenza A virus pandemics continue to occur sporadically in the human population. Moreover, the emergence of a novel avian-origin reassortant influenza A (H7N9) virus in China with several characteristic features of mammalian influenza viruses poses concern for public health [1]. Currently, vaccination using inactivated influenza virus preparations remains the primary method of prevention, especially for pre-pandemic vaccines. In particular, A/PR/8/34 (PR8)-based pre-pandemic vaccine candidates, which contain the internal gene segments of PR8 virus and the HA and NA genes from avian influenza viruses with pandemic potential, have been generated and in some cases improved with respect to their

\footnotetext{
* Correspondence: mariarita.castrucci@iss.it

${ }^{\dagger}$ Equal contributors

${ }^{1}$ Department of Infectious, Parasitic and Immune-Mediated Diseases, Istituto

Superiore di Sanità, Viale Regina Elena, 299, 00161 Rome, Italy

Full list of author information is available at the end of the article
}

growth characteristics [2, 3]. However, while vaccineelicited antibodies will fully protect against homologous virus infection, eventually they offer only marginal protection against heterologous drift virus infection.

Although heterosubtypic immunity in humans appears to be weak, there is evidence that cross-reactive cellmediated immune responses contribute to disease control [4-8]. Thus, vaccine-induced primary and memory responses by $\mathrm{T}$ cells against the relatively conserved internal antigens of influenza could play an important role in reducing the severity of disease caused by antigenic variants that could arise [9-13]. Although non-replicating influenza virus-based vaccines are known to be poor inducers of cytotoxic $\mathrm{T}$ cell (CTL) responses, advances in the field of adjuvants, delivery systems, and novel vaccination strategies hold promise for improving their potential effectiveness [14-17]. Inactivated whole virus vaccines with intact membrane fusion activity are known to facilitate crosspresentation to $\mathrm{CD} 8+\mathrm{T}$ cells by antigen presenting cells 
(APC), and are more immunogenic than split vaccines $[18,19]$. Moreover, gamma-ray-inactivation of whole-virus vaccines has been reported to preserve antigenicity, as well as cellular and humoral immunogenicity, to a greater extent than current viral inactivation methods [20]. Despite the important role that multiple antigenic determinants of internal viral proteins may have in protection against infection, little is yet known about which of these antigens would better induce and/or recall memory CD8+ $\mathrm{T}$ cells after in vivo administration of an inactivated whole virus vaccine.

Because of different HLA haplotypes and MHC Class I-dependent CD8+ $\mathrm{T}$ cell functions, the quality and quantity of a $\mathrm{T}$ cell response can vary greatly between individuals. HLA-A*0201 is an allele expressed by nearly half of the world's population and several studies have been performed to determine the HLA-A2-restricted $\mathrm{CD} 8+\mathrm{T}$ cell responses following natural influenza virus infection $[21,22]$. In the present study, we investigated the HLA-A*0201-restricted epitope specificities of CD8+ $\mathrm{T}$ cells in HLA-A2.1 transgenic (AAD) mice responding to a non-replicating H7N3 whole virus, and revealed the breadth of recall responses following infection of these mice with heterologous PR8 virus. We also determined whether these vaccine-induced virus-specific CD8+ T cells, which target the internal conserved viral proteins, affected virus replication in the lungs of the mice.

\section{Methods}

\section{HLA-A2.1 transgenic mice}

AAD mice were obtained from The Jackson Laboratory (Bar Harbor, ME, USA). These mice with the C57BL/6J genetic background express an interspecies hybrid class I molecule, composed of the alpha 1 and alpha 2 domains of the human HLA-A*0201 allele and the alpha 3, cytoplasmic and transmembrane domains of the mouse $\mathrm{H}$ $2 \mathrm{D}^{\mathrm{d}}$ class I molecule [23]. Female mice were used at 8-10 weeks of age; genetic authenticity was confirmed by performing PCR for the transgene. All mice were maintained at Istituto Superiore di Sanità following institutional guidelines and were used under approved protocols.

\section{Peptides}

The $\mathrm{H} 2-\mathrm{D}^{\mathrm{b}}$ restricted $\mathrm{NP}_{366}$ peptide and thirteen peptides that bind the HLA-A2.1 molecule and are conserved among diverse influenza subtypes were synthesized by Primm (Italy). Peptide purity was $>90 \%$ in all cases, and the identity of the peptides was verified by using spectrometry. The peptides were dissolved in DMSO at $10 \mathrm{mg} / \mathrm{ml}$ and stored at $-20{ }^{\circ} \mathrm{C}$.

\section{Generation of PR8-NP $\mathrm{N} 370 \mathrm{Q}_{\text {virus }}$}

The mutant recombinant virus $\mathrm{PR} 8-\mathrm{NP}_{\mathrm{N} 370 \mathrm{Q}}$, in which the asparagine at the fifth position of the epitope was replaced with glutamine $(\mathrm{N} 370 \mathrm{Q})$, was generated by using plasmid-driven reverse genetics, as described by Neumann et al. [24]. The presence of the NP mutation was confirmed by sequencing PCR-amplified cDNA.

\section{Immunization of mice and challenge experiments}

Groups of AAD mice were injected intraperitoneally (i.p.) with $500 \mathrm{HAU}$ (approximately $3.5 \mu \mathrm{g}$ of viral protein in a 0.5 -ml volume) of either live or heat-inactivated (HI) low pathogenic A/turkey/Italy/214845/02 virus (HI-H7N3). Heat inactivation of small volumes of virus suspension was performed in a water bath at $56{ }^{\circ} \mathrm{C}$ for $30 \mathrm{~min}$ and confirmed by the complete loss of infectivity of MDCK cells. Intranasal (i.n.) immunization was performed by anesthetizing mice with Avertin (2,2,2-tribromoethanol) and then inoculating them with $10^{2.4} \mathrm{TCID}_{50}$ of PR8 virus, resuspended in $40 \mu \mathrm{l}$ of PBS. For the viral challenge, mice in groups of 7 were i.n. infected with $3 \mathrm{LD}_{50}$ (50\% lethal dose), corresponding to $10^{3.7} \mathrm{TCID}_{50}$ in a volume of $40 \mu \mathrm{l}$, of $\mathrm{PR} 8-\mathrm{NP}_{\mathrm{N} 370 \mathrm{Q}}$ virus. Naïve mice were included as a negative control. The mice were weighted daily and monitored for mortality for two weeks. To determine viral lung titers, mice were sacrificed 3 and 7 days post-infection (p.i.), and lung homogenates were titrated in MDCK cells. The limit of viral detection was $0.5 \log _{10} \mathrm{TCID}_{50} / \mathrm{ml}$.

\section{IFN- $\gamma$ ELISPOT assays}

Spleens of mice (5-7 mice per group) were collected at the indicated time points and assayed for antigen-specific IFN- $\gamma$-producing cells by using an IFN- $\gamma$ ELISPOT assay. In the challenge experiments, inflammatory cells were also collected from the lymph nodes draining the respiratory tracts (mediastinal lymph nodes, MLN), lungs and bronchoalveolar lavages (BAL) of infected mice as previously described, and then directly subjected to the ELISPOT assay $[25,26]$. Single-cell suspensions from the lymphocytic populations were cultured with the indicated synthetic peptides or DMSO in anti-IFN- $\gamma$-coated plates at $37{ }^{\circ} \mathrm{C}$ for $36-40 \mathrm{~h}$. Colored spots representing IFN- $\gamma$ releasing cells are reported as the number of spot-forming cells (SFC) per $10^{6}$ cells.

\section{Serology}

Serum samples were collected from mice vaccinated with HI-H7N3 immediately before and 7 days after challenge, and tested for the presence of influenza-specific antibodies by using an hemagglutination-inhibition (HI) assay and a micro-neutralization (MN) assay, as described previously [27]. Sera were also tested in ELISA, using purified whole inactivated viruses [28]. 


\section{Statistics}

The statistical significance of the differences between groups of animals was determined by using the WilcoxonMann-Whitney test; $P<0.05$ was considered significant.

\section{Results}

Induction of influenza-specific CD8+ T cell responses in $A A D$ mice following vaccination with $\mathrm{H} 7 \mathrm{~N} 3$ virus

The initial experiments were designed to determine the breadth and specificity of primary CD8+ $\mathrm{T}$ cell responses that were elicited against the internal viral proteins in $\mathrm{AAD}$ mice following i.p. immunization with the same dose of live or HI-H7N3 virus. To this end, a panel of influenza-derived CD8 + T cell epitope peptides (see Table 1), consisting of 1 nucleoprotein (NP) epitope, 10 polymerase epitopes, and 2 matrix (M1) epitopes, was used in IFN- $\gamma$ ELISPOT assays because they are highly conserved among different influenza subtypes. These CD8+ T cell epitopes were previously reported to be generated by natural processing of influenza antigens in HLA-A2+ donors and were found to be immunogenic following subcutaneous injection of HLA-A2/ $\mathrm{K}^{\mathrm{b}}$ transgenic mice [21, 22, 29].

Although the intramuscular or intranasal route is used for vaccination in humans, the i.p. route of viral inoculation does not permit productive influenza replication in mice, and it is used to examine CD8+ T cell responses in many studies performed in murine models of influenza virus infection [30-32]. When mice were injected i.p. with the live H7N3 virus, all the selected peptides containing dominant and subdominant $\mathrm{T}$ cell epitopes stimulated IFN- $\gamma$ secretion from mouse splenocytes in ex vivo ELISPOT assays (Fig. 1a). In particular, a strong CD8+ T cell response to the HLA-A2-restricted immunodominant

Table 1 Influenza A virus-derived MHC class I restricted T cell epitopes included in the study

\begin{tabular}{llll}
\hline Peptides & Sequence & Position & MHC restriction \\
\hline M1-58 & GILGFVFTL & $58-66$ & HLA-A2.1 \\
M1-59 & ILGFVFTLTV & $59-68$ & HLA-A2.1 \\
PB1-407 & MMMGMFNML & $407-415$ & HLA-A2.1 \\
PB1-413 & NMLSTVLGV & $413-421$ & HLA-A2.1 \\
PB1-501 & FVANFSMEL & $501-509$ & HLA-A2.1 \\
PB1-505 & FSMELPSFGV & $505-514$ & HLA-A2.1 \\
PB2-49 & WMMAMKYPI & $49-57$ & HLA-A2.1 \\
PB2-50 & MMAMKYPITA & $50-59$ & HLA-A2.1 \\
PA-46 & FMYSDFHFI & $46-54$ & HLA-A2.1 \\
PA-86 & RTMAWTWNSI & $86-96$ & HLA-A2.1 \\
PA-225 & SLENFRAY & $225-233$ & HLA-A2.1 \\
PA-282 & FLLMDALKL & $282-290$ & HLA-A2.1 \\
NP-329 & QLVWMACHSAA & $329-339$ & HLA-A2.1 \\
NP-366 & ASNENMETM & $336-374$ & H2-D ${ }^{b}$ \\
\hline
\end{tabular}

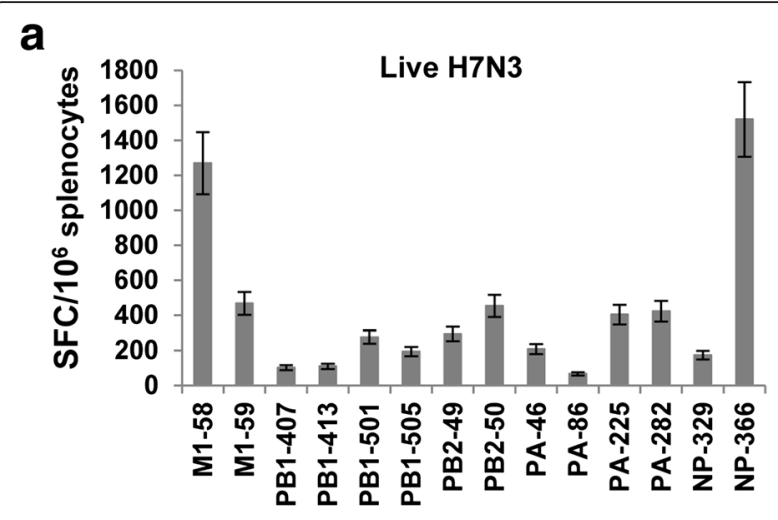

b

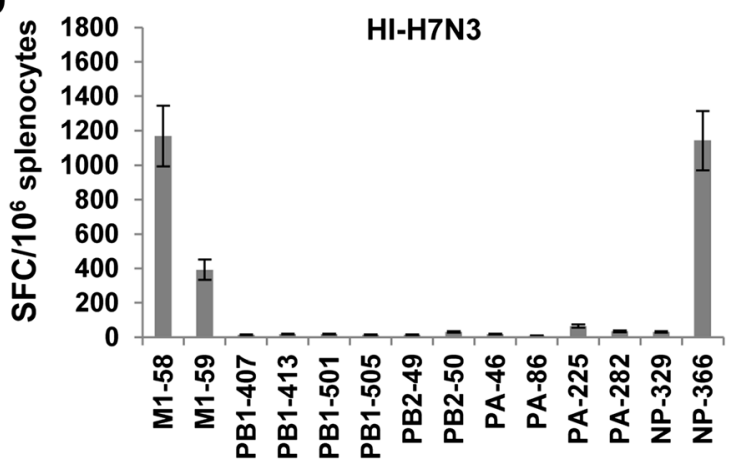

Fig. 1 HLA-A2-restricted influenza-specific CD8 + T cell responses in AAD mice. Groups of AAD mice (5/group) were immunized i.p. with $500 \mathrm{HAU}$ of live (a) or heat-inactivated (HI)-H7N3 virus (b). Twelve days later, influenza-specific CD8+ T cell responses were measured in cells from freshly isolated splenocytes of individual mice by use of an ex vivo IFN- - -ELISPOT assay with the indicated peptides. Bars represent means \pm standard deviation (SD) for five mice per group. The data are representative of three independent experiments that gave similar results

$\mathrm{M}_{58}$ epitope was observed in all mice. This is in accordance with previous studies in AAD mice showing that CTL recognition of the $M 1_{58}$ peptide in the context of the alpha $1+$ alpha 2 domains was greatly augmented by replacing the human alpha 3 domain with its murine counterpart in the transgenic class I molecule [23]. The immunodominant peptide epitope $\mathrm{NP}_{366}$ was also included in the assay to document the $\mathrm{H} 2-\mathrm{D}^{\mathrm{b}}$-restricted $\mathrm{CD} 8+\mathrm{T}$ cell response that has always been observed in these AAD transgenic mice with the C57BL/6J genetic background [33]. Interestingly, the responses specific to peptide epitope $\mathrm{H} 2-\mathrm{D}^{\mathrm{b}}-\mathrm{PA}_{224}$ were weaker in these mice compared with the co-dominant $\mathrm{CD} 8$ reactivity with the $\mathrm{H} 2-\mathrm{D}^{\mathrm{b}}-\mathrm{NP}_{366}$ epitope that has previously been measured in $\mathrm{C} 57 \mathrm{BL} / 6 \mathrm{~J}$ mice following primary virus infection (data not shown and [34]). Similar reactivity to $\mathrm{H} 2-\mathrm{D}^{\mathrm{b}}-\mathrm{PA}_{224}$ was also measured with the overlapping $\mathrm{PA}_{225}$ peptide epitope, which was recognized by memory $\mathrm{CD} 8+\mathrm{T}$ cells in $\mathrm{A} 2+$ healthy donors [22]. 
For this reason, the murine peptide epitope $\mathrm{H} 2-\mathrm{D}^{\mathrm{b}}$ $\mathrm{PA}_{224}$ was not included in the analysis.

In contrast to the live viral infection, mice immunization with HI-H7N3 virus, which maintains fusion activity, elicited CD8+ T cell responses that were mainly directed at immunodominant epitopes $\mathrm{M}_{58}$ and $\mathrm{H} 2-\mathrm{D}^{\mathrm{b}}-\mathrm{NP}_{366}$. Reproducible $\mathrm{T}$ cell responses were also observed for the overlapping peptide $\mathrm{M}_{59}$, whereas undetectable or lower numbers (50-80 SFC/10 ${ }^{6}$ cells) were consistently measured for the other subdominant epitopes, compared with those measured in mice infected with live virus (Fig. 1b).

Together, these data indicate that a broad repertoire of CD8 + T cell specificities are elicited in AAD mice upon i.p. injection of live influenza virus, and that vaccination with non-replicating H7N3 virus narrows the immune response to the immunodominant epitopes.

Induction of CD8+ T cell recall responses to internal viral proteins in mice immunized with $\mathrm{HI}-\mathrm{H} 7 \mathrm{~N} 3$ virus and then infected with PR8 virus

To further investigate the immunogenicity of whole inactivated virus vaccines, mice were vaccinated with HI-H7N3 virus and, one month later, i.n. infected with a sublethal dose of PR8 virus. Then, virus-specific CD8+ T cell responses were examined on day 7 p.i. by measuring IFN- $\gamma$ production from splenocytes in an ELISPOT assay in the presence of the above-mentioned peptides. Primary infection of control mice with PR8 virus induced CD8+ T cell responses to the immunodominant $\mathrm{H} 2-\mathrm{D}^{\mathrm{b}}-\mathrm{NP}_{366}$ and $\mathrm{M} 1_{58}$ epitopes and to other HLA-A2 restricted subdominant epitopes (Fig. 2a). When mice were vaccinated with HI-H7N3 prior to PR8 virus infection, the frequencies of immunodominant epitopes increased at least 3-fold in the spleens, whereas the frequencies of the subdominant epitopes were similar to those observed in unvaccinated mice (Fig. 2b).

These results provide further evidence that HI-H7N3 virus could prime $\mathrm{CD} 8+\mathrm{T}$ cell responses specific to the immunodominant $\mathrm{T}$ cell epitopes that were rapidly recalled following viral infection.

\section{Induction of influenza-specific CD8+ T cell responses} by vaccination with $\mathrm{HI}-\mathrm{H} 7 \mathrm{~N} 3$ virus in the presence of pre-existing immunity to influenza virus

We next sought to determine whether prior exposure of mice to a heterologous influenza virus affected the immunogenicity of the HI-H7N3 vaccine. Groups of mice were i.n. primed with sublethal doses of PR8 virus, and then six weeks later vaccinated i.p. with the HI-H7N3 virus. As shown in Fig. 3, the HI-H7N3 virus boosted the CD8+ T cell responses specific to the immunodominant epitopes in the presence of pre-existing immunity to influenza. Specifically, a 3- to 5-fold increase was measured for the dominant $\mathrm{M}_{58}$ and $\mathrm{H} 2-\mathrm{D}^{\mathrm{b}}-\mathrm{NP}_{366}$

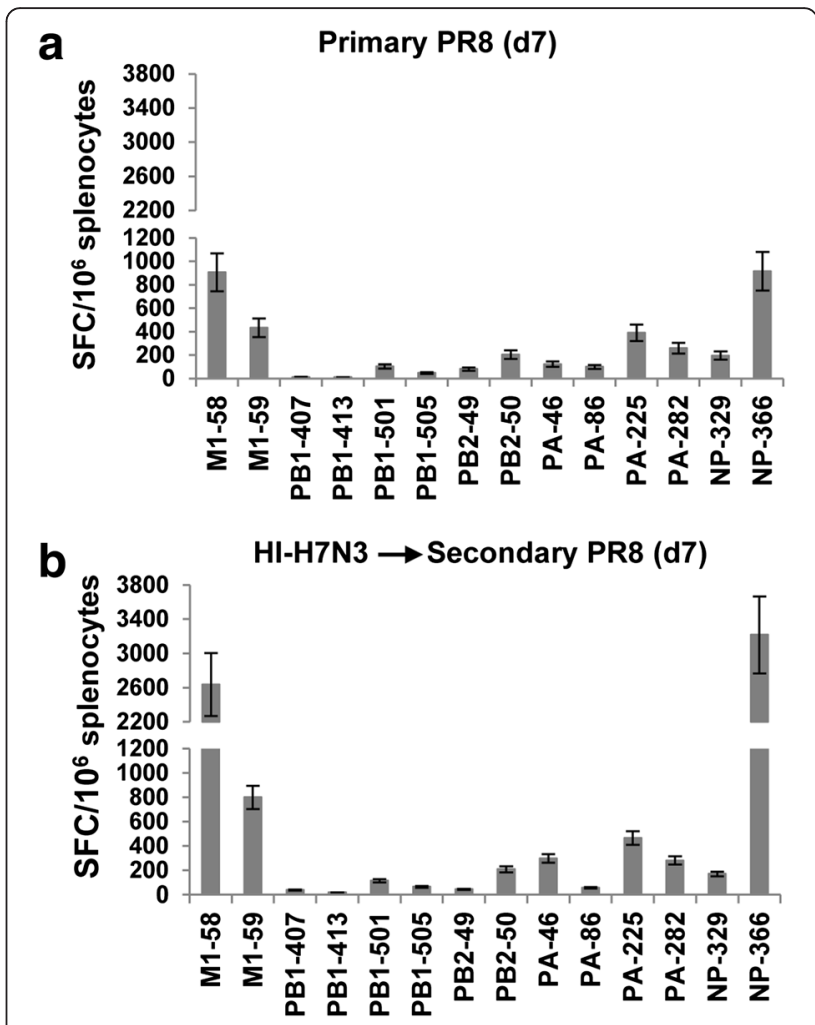

Fig. 2 HLA-A2-restricted influenza recall responses in mice immunized with $\mathrm{HI}-\mathrm{H} 7 \mathrm{~N} 3$ virus and then infected with PR8 virus. Naïve mice (a) or mice vaccinated with $\mathrm{HI}-\mathrm{H} 7 \mathrm{~N} 3$ virus 4 weeks earlier (b) (5/group) were challenged i.n. under anesthesia with $10^{2.4} \mathrm{TCID}_{50}$ of PR8. Seven days after challenge, mice were sacrificed and influenza-specific CD8+ T cell responses were measured in cells from freshly isolated splenocytes of individual mice by means of an ex vivo IFN- $\gamma$-ELISPOT assay with the indicated peptides. Bars represent means \pm SD for five mice per group. The data are representative of two independent experiments that gave similar results

peptides, relative to the mice that received only the PR8 virus, whereas the frequency of the immune effectors specific to the subdominant epitopes was at a similar low level in both groups of mice, regardless of preexisting host immunity to the virus. Overall, these data show that the inactivated whole virus vaccine could induce recall responses to the $\mathrm{H} 2-\mathrm{D}^{\mathrm{b}}-\mathrm{NP}_{366}$ and $\mathrm{M} 1_{58^{-}}$ specific epitopes.

Virus load in the lungs of HI-H7N3 virus-vaccinated mice upon challenge with a heterologous influenza virus Previous studies have shown the protective efficacy of $\mathrm{M} 1_{58}$-specific $\mathrm{CD} 8+\mathrm{T}$ cells against virus infection in HLA-A2 mice $[35,36]$. Our results suggest that the $\mathrm{CD} 8+\mathrm{T}$ cell cross-reactivity between the internal proteins of PR8 virus and the non-replicating HI-H7N3 vaccine in $A A D$ mice involves the $\mathrm{M}_{58}$ and $\mathrm{H} 2-\mathrm{D}^{\mathrm{b}}$ $\mathrm{NP}_{366}$ epitopes. To evaluate whether the $\mathrm{M1}_{58}$-specific $\mathrm{T}$ cells elicited by HI-H7N3 may play a role in protection 


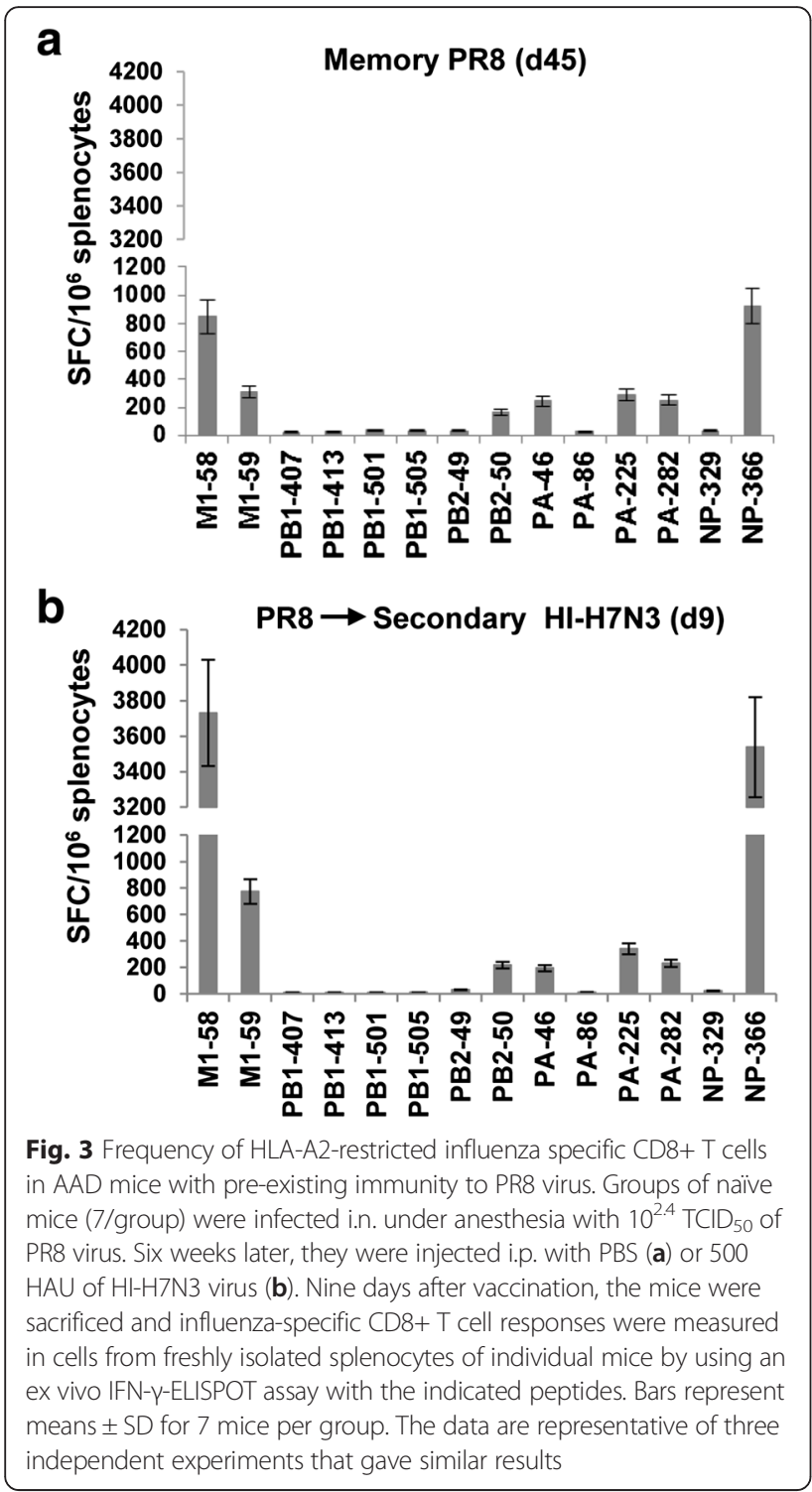

against challenge virus replication, we generated the recombinant influenza virus $\mathrm{PR} 8-\mathrm{NP}_{\mathrm{N} 370 \mathrm{Q}}$, in which the anchor residue of the $\mathrm{H} 2-\mathrm{D}^{\mathrm{b}}-\mathrm{NP}_{366}$ epitope that binds the murine $\mathrm{H} 2-\mathrm{D}^{\mathrm{b}}$ MHC-I glycoprotein is mutated. This mutation results in the absence of $\mathrm{H}_{2}-\mathrm{D}^{\mathrm{b}}-\mathrm{NP}_{366}$ complexes and a lack of CD8+ T cell recognition, that correlates with a more severe disease, in spite of comparable lung virus titers with those of mice infected with the wild-type PR8 virus [31] (Fig. 4). We used this virus to investigate whether cross-reactive $\mathrm{CD} 8+\mathrm{T}$ cells could limit the infection in mice vaccinated with HI-H7N3 virus and subsequently challenged with lethal doses of PR8-NP $\mathrm{N}_{370 \mathrm{Q}}$ virus. A single dose of a parenterally administered vaccine was not capable to improve mouse survival and weight loss in this viral challenge model (data not shown). Nevertheless, the viral load in the lungs of the immunized mice was reduced at 7 days post-

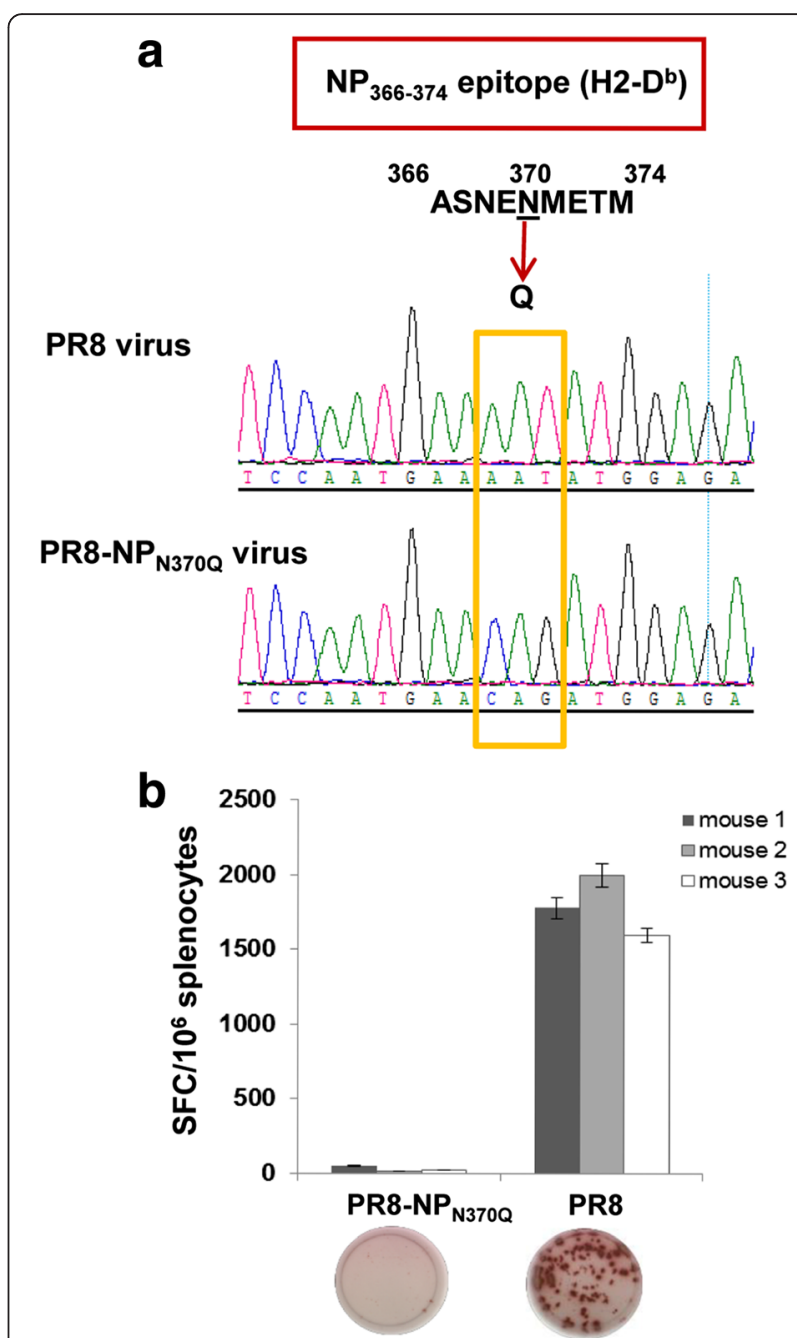

Fig. 4 Amino acid mutation in the $\mathrm{H}_{2}-\mathrm{D}^{\mathrm{b}}-\mathrm{NP}_{366}$ epitope and CD8+ $T$ cell recognition following virus infection in AAD mice. a Sequence electropherograms showing the change from Asparagine $(N)$ to Glutamine (Q) at position 370 in the $\mathrm{H}_{2}-\mathrm{D}^{\mathrm{b}}-\mathrm{NP}_{366}$ epitope of the PR8-NP ${ }_{N 370 Q}$ virus. b Mice were infected i.n. with $10^{2.4} \mathrm{TCID}_{50}$ of PR8 or PR8-NP $\mathrm{N}_{\mathrm{N} 70 \mathrm{Q}}$ virus. Nine days later, the mice were sacrificed and the frequency of $\mathrm{H}_{2}-\mathrm{D}^{\mathrm{b}}$ - $\mathrm{NP}_{366}$-specific IFN- $\mathrm{\gamma}$-producing $\mathrm{T}$ cells was measured by using an ELISPOT assay on spleen-derived lymphocytes from individual mice. Results are expressed as means of triplicate wells \pm SD. The stained wells of representative samples are shown below the graphical representations of the number of spot forming units (SFU) per $10^{6}$ cells

challenge by 20-to 40 -fold compared with the control mice (Fig. 5). A vigorous recall response of CD8+ T cells targeting the $\mathrm{M}_{58}$ epitope was measured in the spleen of these mice compared with the non-immunized mice. Moreover, the recruitment of high levels of antigen-driven IFN- $\gamma$-producing CD8+ cells to the airways and infected lung by day 5 post-challenge suggests that the crossreactive $\mathrm{M} 1_{58}$-specific CD8+ T cells were likely responsible for the reduced lung viral loads (Fig. 6a). 


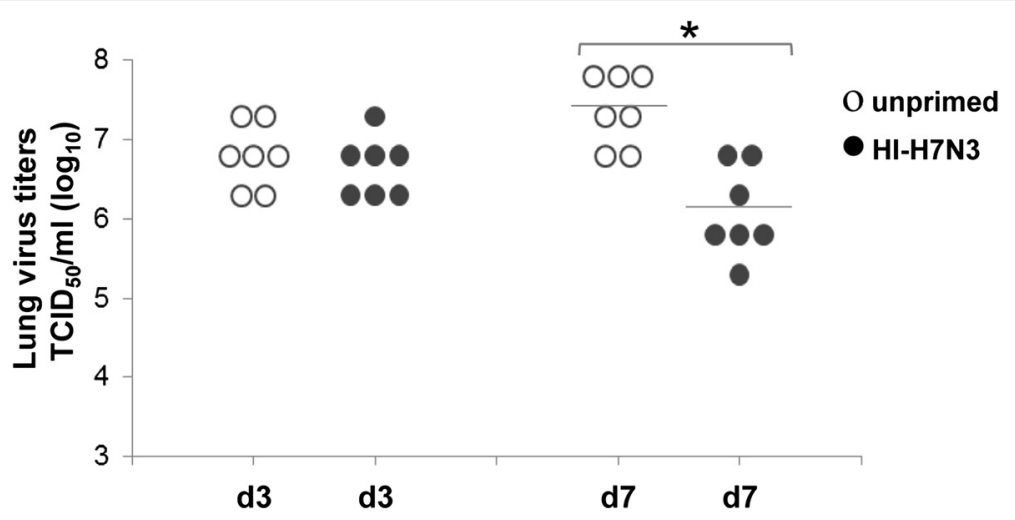

Fig. 5 Viral load levels in the lungs of mice following infection with PR8-NP ${ }_{N 3700}$ virus. Groups of mice (7/group) immunized with the HI-H7N3

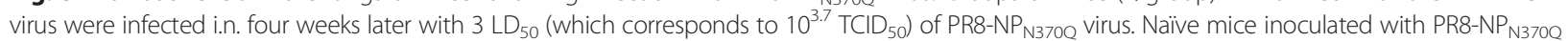
virus served as controls. Three days and seven days after challenge, mice were sacrificed and lungs were collected for viral titration on MDCK cells. Virus titers from individual mice are presented as $\log _{10} T C I D_{50}$ per $\mathrm{ml}$ (expressed as the mean $\pm S D \log _{10} T C I D_{50} / g$ of tissue). One of three similar experiments is shown. ${ }^{*} P<0.005$ compared with unprimed mice
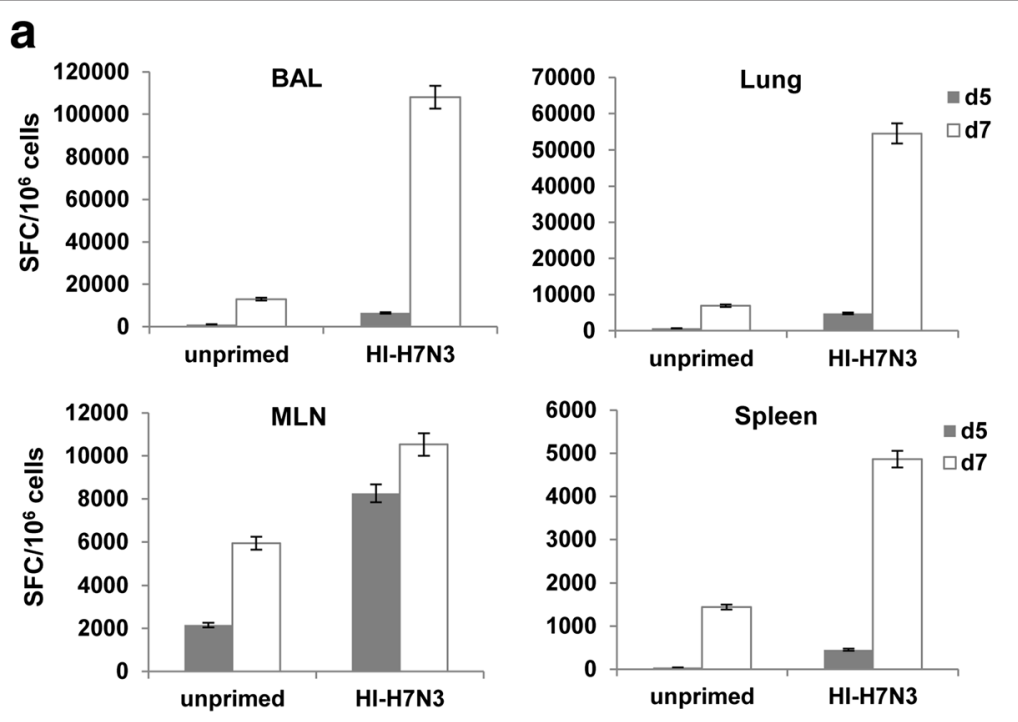

b
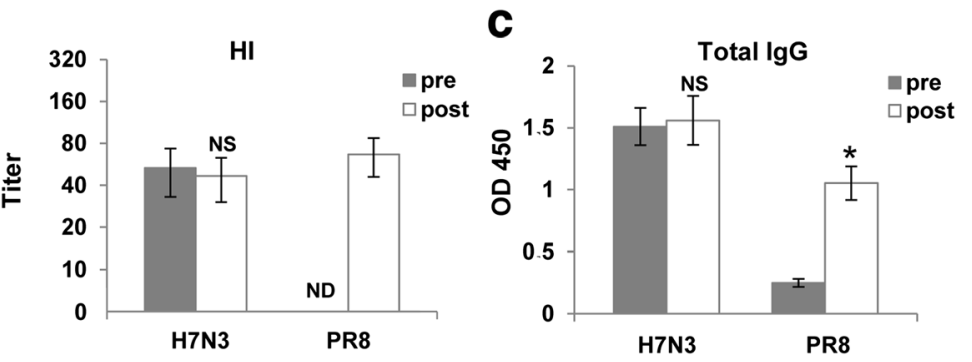

Fig. 6 Quantification of $\mathrm{M}_{58}$-specific CD8 + T cells isolated from lung airways and lymphoid organs, and influenza-specific antibodies following PR8-NP $\mathrm{N}_{370 \mathrm{Q}}$ challenge. Groups of mice were treated as described in the legend for Fig. 5. a On day 5 or day 7 post-challenge, the mice were sacrificed and the numbers of $M 1_{58}$-specific CD8+ T cells were examined in the BAL, lungs, MLN, and spleen by using the IFN- $\gamma$-ELISPOT assay. Results are expressed as means of triplicate wells \pm SD. $\mathbf{b}$ \& $\mathbf{c}$ Serum samples were drawn before (pre) and 7 days post-challenge (post) from mice previously immunized with the HI-H7N3 virus, and specific antibodies against H7N3 and PR8 viruses were measured by HI (b) and ELISA (c); ELISA for lgG antibodies; values for sera were obtained with use of 100-fold-diluted samples. ND = None detected. OD $450=0$ tical density at $450 \mathrm{~nm}$. Values represent mean of 6 mice per group \pm SD. One of three similar experiments is shown. ${ }^{*} P<0.05, N S=$ not significant, compared with pre-challenge sera 
To exclude the possibility that cross-reactive antibodies could also have contributed to this viral control, pre-challenge sera obtained from mice that received the $\mathrm{HI}-\mathrm{H} 7 \mathrm{~N} 3$ vaccine, and post-challenge sera were analyzed for the presence of influenza-specific antibodies. After immunization with HI-H7N3 vaccine, mice developed virus-specific antibodies that were detected by $\mathrm{HI}$ assay that did not cross-react with PR8 virus (Fig. 6b). Similar results were observed in the $\mathrm{MN}$ assay (data not shown). When tested against detergent-disrupted viruses by ELISA, pre-challenge sera as well as post-challenge sera showed similar antibody levels against the H7N3 virus. In contrast, only post-challenge sera showed high levels of reactivity against the PR8 virus (Fig. 6c).

Overall, our results show that cross-protective cellular immune responses can be induced in AAD mice following systemic immunization with an inactivated whole-virus influenza vaccine.

\section{Discussion}

In the present study, we evaluated CD8 + T cell responses to internal viral proteins elicited by an inactivated H7N3 virus in $\mathrm{AAD}$ mice. We found that $\mathrm{CD} 8+\mathrm{T}$ cell responses to both the immunodominant epitopes and to most of the highly conserved subdominant epitopes could be detected in AAD mice upon inoculation with live virus, whereas immunization with $\mathrm{HI}-\mathrm{H} 7 \mathrm{~N} 3$ virus induced $\mathrm{CD} 8+\mathrm{T}$ cell responses mainly to the immunodominant epitopes. We also found that the vaccine-induced $\mathrm{T}$ cell responses appeared to reduce the lung viral load in mice challenged with the $\mathrm{PR} 8-\mathrm{NP}_{\mathrm{N} 370 \mathrm{Q}}$ virus, which lacks the $\mathrm{H} 2-\mathrm{D}^{\mathrm{b}}$ $\mathrm{NP}_{366}$ epitope.

Most influenza-specific memory $\mathrm{T}$ cells that are detectable in humans are directed mainly against the remarkably conserved epitopes of the internal viral proteins, and have been reported to accumulate either as resident or central memory $\mathrm{T}$ cells in the lungs and lymphoid tissues, respectively, following recovery from influenza virus infections [37-41]. Therefore, the rapid boosting of these crossreactive $\mathrm{T}$ cells in the respiratory tract by a pre-pandemic vaccine could be extremely beneficial to provide protection against severe influenza virus infections [42]. Here, the $\mathrm{CD} 8+\mathrm{T}$ cell responses to the HLA-A2-restricted influenza epitope $\mathrm{M}_{58}$ paralleled those specific to the $\mathrm{H} 2$ $\mathrm{D}^{\mathrm{b}}-\mathrm{NP}_{366}$ epitope in AAD mice, following immunization with live virus. Interestingly, the level of responses specific to the $\mathrm{H} 2-\mathrm{D}^{\mathrm{b}}-\mathrm{PA}_{224}$ epitope was lower in AAD mice than in C57BL/6 mice. This low reactivity may reflect a reduced level of antigen-specific $\mathrm{T}$ cell precursors in AAD mice, compared with the higher frequency of naïve precursors for $\mathrm{H} 2-\mathrm{D}^{\mathrm{b}}-\mathrm{PA}_{224}$ than $\mathrm{H} 2-\mathrm{D}^{\mathrm{b}}-\mathrm{NP}_{366}$ in C57BL/6 mice [43]. Alternatively, it may be due to superior competition of $\mathrm{T}$ cells specific to the $\mathrm{H} 2-\mathrm{D}^{\mathrm{b}}-\mathrm{NP}_{366}$ and $\mathrm{M} 1_{58}$ epitopes from the most abundant internal proteins during antigen presentation.

In AAD mice immunized with a single dose of inactivated $\mathrm{H} 7 \mathrm{~N} 3$ vaccine, $\mathrm{CD} 8+\mathrm{T}$ cell responses were mainly elicited by immunodominant epitopes. Several factors contribute to the differences between live and inactivated viruses in the $\mathrm{CD} 8+\mathrm{T}$ cell response to the subdominant epitopes. In particular, the provision of additional antigens in the form of endogenously synthesized viral proteins, following infection with a live virus, plays a key role. Our results are consistent with those of other studies showing that epitopes derived from more abundant viral proteins contribute to immunodominant responses, although the inherent features of the antigens and their capacity to be cross-presented by APC also likely play a role [32, 44-46]. Likewise, others have reported that CTL induction by cross-presentation of Lymphocytic Choriomeningitis virus antigens, that were constitutively expressed in tumor cell lines and injected in mice, was driven by immunodominant but not subdominant epitopes [47]. To further investigate the immunogenicity of the whole inactivated virus vaccine, we used HI-H7N3 in a prime-boost approach with live preparations of serologically distinct PR8 virus. We detected and efficiently recalled, upon subsequent viral infection, mainly CD8+ T cell responses that were restricted to the immunodominant epitopes $\mathrm{H} 2-\mathrm{D}^{\mathrm{b}}-\mathrm{NP}_{366}$ and $M 1_{58}$, and the overlapping $M 1_{59}$. Importantly, the $\mathrm{M1}_{58}$-specific CD8+ $\mathrm{T}$ cells were efficiently recruited to the respiratory tract by subsequent i.n. infection with PR8-NP ${ }_{\mathrm{N} 370 \mathrm{Q}}$ virus, and were likely responsible for the reduction in lung viral load. Although we cannot exclude that $\mathrm{CD} 4+$ and $\mathrm{CD} 8+\mathrm{T}$ cells with other specificities may help reduce viral infection, the lack of serum crossreactive antibodies further corroborates the most likely protective effect of $\mathrm{M}_{58}$-specific CD8+ T cells. Nevertheless, no changes were observed in mortality of these mice receiving a single dose of a parenterally administered vaccine as compared to unvaccinated mice. Our results agree with other research findings showing that a subsequent influenza virus infection in the respiratory tract is required for reactivation of i.p. primed influenza virus-specific $\mathrm{CD} 8+\mathrm{T}$ cells and access to the lung airways $[38,48]$. Indeed, activation and maintenance of $\mathrm{T}$ cell populations in the airways are dependent upon the route of infection and prolonged presentation of viral antigens in the lymph nodes draining the respiratory tract. Thus, new immunization strategies that induce broadly crossreactive antibodies and $\mathrm{T}$-cell responses at mucosal surfaces could greatly improve influenza vaccine efficacy. Although mouse models do not closely reflect human influenza virus infection, yet our data suggest that a single immunization with a whole inactivated influenza virus vaccine might also be able to elicit or recall cross-protective immune responses specific to immunodominant NP and 
M epitopes in humans, and thus, to some extent, counteract an infection by an heterologous virus. In this context, it would be interesting to explore the immunogenic pattern and magnitude of the response elicited in the presence of adjuvants or following immunization of these mice with live, attenuated influenza vaccine (LAIV). Previous studies have shown quantitative and qualitative differences in $\mathrm{T}$ cell responses to LAIV and inactivated vaccines. In particular, viral replication of LAIV in the respiratory mucosa, especially of young children with low levels of pre-existing immunity, provides better protection against infection, likely due to a broader array of dominant and subdominant $\mathrm{T}$ cell responses as well as beneficial induction of immuneeffectors at the site of infection $[49,50]$.

The $M 1_{58}$ epitope is highly conserved among multiple influenza viral strains and subtypes, and it is able to elicit CTL responses in both HLA-A*02- and HLAC*08-positive individuals $[29,51]$. Although functional constraints on influenza virus CTL epitopes may limit escape from CTL-mediated immunity, epitope mutations may occur and, in some cases, these variant epitopes can still be recognized, to some extent, by cross-reactive $\mathrm{T}$ cells [52-54]. Indeed, CTL escape variants have been shown to arise following independent amino acids mutations either at the anchor residues or in the T cell receptor contact residues of CTLs specific to the NP of influenza A viruses isolated during circulation in human populations $[55,56]$. For these reasons, it is strongly desirable to have more epitopes recognized by the immune system to fight a viral infection. Furthermore, we cannot exclude the possibility that inactivated whole virus-based vaccines of avian origin would cross-react better than PR8-based vaccines against new emerging zoonotic influenza viruses in human hosts. Although viral internal proteins are highly conserved, the $10 \%-15 \%$ sequence dissimilarity in the NP of different influenza subtypes, for example, may be responsible for the loss of epitopes of unknown HLA restrictions. Therefore, in the context of inactivated vaccines against highly pathogenic influenza strains that could arise from animal reservoirs, the recall of dominant CD8+ $\mathrm{T}$ cell responses targeting the $\mathrm{M}$ and NP proteins most closely related to the emerging virus strains could be of great value in vaccine effectiveness. Further studies are warranted to better characterize the relationship between pre-existing CD8+ T-cell immunity across the multiple ethnicities established in the human population and epitope conservancy among the internal proteins of potentially pandemic influenza strains [57].

\section{Conclusion}

In summary, our data show that a non-replicating whole virus-based vaccine elicited cross-reactive influenza virus-specific $\mathrm{CD} 8+\mathrm{T}$ cell responses that were restricted predominantly to immunodominant epitopes, and that substantial numbers of effector-memory $\mathrm{T}$ cells were recruited into the lungs of $\mathrm{AAD}$ mice for protection against heterologous virus infection. Vaccination strategies designed to improve the induction of or to boost immune responses to the most conserved epitopes of newly emerging influenza A virus strains would be extremely useful for the development of pre-pandemic vaccines.

\section{Competing interests}

The authors declare that they have no competing interests.

\section{Authors' contributions}

Designed the experiments: MRC and BG; Performed the experiments: BG, GDM, ES, MF; Analyzed the data: BG, GDM, ID and MRC; Wrote the paper: BG, MRC. All authors read and approved the final manuscript.

\section{Acknowledgments}

We thank Andrea Giovannelli for assistance with the animal experiments and Susan Watson for scientific editing. This work was funded by the European Union's Seventh Framework Programme under grant agreement 201169 (Identification of Mechanisms Correlating with Susceptibility for Avian Influenza, IMECS), and by the Ministry of Health, Italy (Exploiting immune cross-reactivity to influenza viral antigens for successful pre-pandemic vaccines, RF-2010-2318269).

\section{Author details}

'Department of Infectious, Parasitic and Immune-Mediated Diseases, Istituto Superiore di Sanità, Viale Regina Elena, 299, 00161 Rome, Italy. ${ }^{2}$ Department of Biology and Biotechnology "Charles Darwin", Sapienza University of Rome, 00185 Rome, Italy.

Received: 12 January 2016 Accepted: 23 March 2016

Published online: 31 March 2016

\section{References}

1. Gao R, Cao B, Hu Y, Feng Z, Wang D, Hu W, Chen J, et al. Human infection with a novel avian-origin influenza A (H7N9) virus. N Engl J Med. 2013;368: 1888-97.

2. Harvey R, Nicolson C, Johnson RE, Guilfoyle KA, Major DL, Robertson JS, et al. Improved haemagglutinin antigen content in $\mathrm{H} 5 \mathrm{~N} 1$ candidate vaccine viruses with chimeric haemagglutinin molecules. Vaccine. 2010;28:8008-14.

3. Abt M, De Jonge J, Laue M, Wolff T. Improvement of H5N1 influenza vaccine viruses: influence of internal gene segments of avian and human origin on production and hemagglutinin content. Vaccine. 2011;29:5153-62.

4. McMichael AJ, Gotch FM, Noble GR, Beare PA. Cytotoxic T-cell immunity to influenza. N Engl J Med. 1983:309:13-7.

5. Grebe KM, Yewdell JW, Bennink JR. Heterosubtypic immunity to influenza A virus: where do we stand? Microbes Infect. 2008;10:1024-9.

6. Wilkinson TM, Li CK, Chui CS, Huang AK, Perkins M, Liebner JC, et al. Preexisting influenza-specific CD4+ T cells correlate with disease protection against influenza challenge in humans. Nat Med. 2012;18:274-80.

7. Sridhar S, Begom S, Bermingham A, Hoschler K, Adamson W, Carman W, et al. Cellular immune correlates of protection against symptomatic pandemic influenza. Nat Med. 2013;19:1305-12.

8. Nayak JL, Richards KA, Yang H, Treanor JJ, Sant AJ. Effect of influenza A(H5N1) vaccine prepandemic priming on CD4+ T-cell responses. J Infect Dis. 2015;211:1408-17

9. Lee LY, Ha Do LA, Simmons C, De Jong MD, Chau NV, Schumacher R, et al. Memory $T$ cells established by seasonal human influenza A infection crossreact with avian influenza $A$ (H5N1) in healthy individuals. J Clin Invest. 2008:118:3478-90.

10. Gras S, Kedzierski L, Valkenburg SA, Laurie K, Liu YC, Denholm JT, et al. Cross-reactive CD8+ T cell immunity between the pandemic H1N1-2009 and H1N1-1918 influenza A viruses. Proc Natl Acad Sci U S A. 2010;107: 12599-604.

11. Van De Sandt CE, Kreijtz JH, De Mutsert G, Geelhoed Mieras MM, Hillaire ML, Vogelzang Van Trierum SE, et al. Human cytotoxic T lymphocytes directed to seasonal influenza A viruses cross-react with the newly emerging H7N9 virus. J Virol. 2014;88:1684-93. 
12. Altenburg AF, Rimmelzwaan GF, De Vries RD. Virus-specific T cells as correlate of cross-protective immunity against influenza. Vaccine. 2015;33:500-6.

13. Chen L, Zanker D, Xiao K, Wu C, Zou Q, Chen W. Immunodominant CD4+ T-cell responses to influenza A virus in healthy individuals focus on matrix 1 and nucleoprotein. J Virol. 2014;88:11760-73.

14. Ennis FA, Cruz J, Jameson J, Klein M, Burt D, Thipphawong J. Augmentation of human influenza A virus-specific cytotoxic T lymphocyte memory by influenza vaccine and adjuvanted carriers (ISCOMS). Virology. 1999;259:256-61.

15. Kim MC, Lee YN, Ko EJ, Lee JS, Kwon YM, Hwang HS, et al. Supplementation of influenza split vaccines with conserved M2 ectodomains overcomes strain specificity and provides long-term cross protection. Mol Ther. 2014;22:1364-74.

16. Durando P, ludici R, Alicino C, Alberti M, De Florentis D, Ansaldi F, et al. Adjuvants and alternative routes of administration towards the development of the ideal influenza vaccine. Hum Vaccin. 2011;7:29-40.

17. Van De Sandt CE, Kreijtz JH, Geelhoed Mieras MM, Vogelzang Van Trierum SE, Nieuwkoop NJ, Van De Vijver DA, et al. Novel G3/DT adjuvant promotes the induction of protective T cells responses after vaccination with a seasonal trivalent inactivated split-virion influenza vaccine. Vaccine. 2014;32:5614-23.

18. Budimir N, Huckriede A, Meijerhof T, Boon L, Gostick E, Price DA, et al. Induction of heterosubtypic cross-protection against influenza by a whole inactivated virus vaccine: the role of viral membrane fusion activity. PLoS One. 2012;7:e30898.

19. Halbroth BR, Heil A, Distler E, Dass M, Wagner EM, Plachter B, et al. Superior in vitro stimulation of human CD8+ T cells by whole virus versus split virus influenza vaccines. PLoS One. 2014;9:e103392.

20. Furuya $Y$. Return of inactivated whole-virus vaccine for superior efficacy. Immunol Cell Biol. 2011;90:571-8.

21. Assarsson E, Bui HH, Sidney J, Zhang Q, Glenn J, Oseroff C, et al. Immunomic analysis of the repertoire of T-cell specificities for influenza A virus in humans. J Virol. 2008;2:12241-51.

22. Gianfrani C, Oseroff C, Sidney J, Chesnut RW, Sette A. Human memory CTL response specific for influenza $A$ virus is broad and multispecific. Human Immunol. 2000;61:438-52.

23. Newberg MH, Smith DH, Haertel SB, Vining DR, Lacy E, Engelhard VH. Importance of $\mathrm{MHC}$ class I a2 and a3 domains in the recognition of self and non-self MHC molecules. J Immunol. 1996;156:2473-80.

24. Neumann G, Watanabe T, Ito H, Watanabe S, Goto H, Gao P, et al. Generation of influenza A viruses entirely from cloned cDNA. Proc Natl Acad Sci U S A. 1999;96:9345-50

25. Garulli B, Meola M, Stillitano MG, Kawaoka Y, Castrucci MR. Efficient vaginato-lower respiratory tract immune trafficking in a murine model of influenza A virus infection. Virology. 2007;361:274-82.

26. Lee S, Miller SA, Wright DW, Rock MT, Crowe Jr JE. Tissue-specific regulation of CD8+ T-lymphocyte immunodominance in respiratory syncytial virus infection. J Virol. 2007;81:2349-58.

27. World Health Organization WHO Global Influenza Surveillance Network. Manual for the Laboratory diagnosis and virological surveillance of influenza. Geneva 27, Switzerland: WHO Press, World Health Organization, 20 Avenue Appia, 1211; 2011.

28. Watanabe T, Watanabe S, Kim JH, Hatta M, Kawaoka Y. Novel approach to the development of effective H5N1 influenza A virus vaccines: use of M2 cytoplasmic tail mutants. J Virol. 2008;82:2486-92.

29. Gotch F, Rothbard J, Howland K, Townsend A, McMichael A. Cytotoxic T lymphocytes recognize a fragment of influenza virus matrix protein in association with HLA-A2. Nature. 1987;326:881-2

30. Flynn KJ, Belz GT, Altman JD, Ahmed R, Woodland DL, Doherty PC. Virusspecific CD8+ T cells in primary and secondary influenza pneumonia. Immunity. 1998:8:683-91.

31. Webby RJ, Andreasky S, Stambas J, Rehg JE, Webster RG, Doherty PC, et al Protection and compensation in the influenza virus-specific CD8+ T cell response. Proc Natl Acad Sci U S A. 2003;100:7235-40.

32. La Gruta NL, Kedzierska K, Pang K, Webby R, Davenport M, Chen W, et al. A virus-specific CD8+ T cell immunodominance hierarchy determined by antigen dose and precursor frequencies. Proc Natl Acad Sci U S A. 2006;103:994-9.

33. Townsend AR, Rothbard J, Gotch FM, Bahadur G, Wraith D, McMichael AJ. The epitopes of influenza nucleoprotein recognized by cytotoxic $T$ lymphocytes can be defined with short synthetic peptides. Cell. 1986;44:959-68

34. Belz GT, Xie W, Altman JD, Doherty PC. A previously unrecognized H-2D restricted peptide prominent in the primary influenza $A$ virus-specific CD8+ T cell response is much less apparent following secondary challenge. J Virol. 2000;74:3486-93.
35. Plotnicky H, Cyblat Chanal D, Aubry JP, Derouet F, Klinguer Hamour C, Beck $A$, et al. The immunodominant influenza matrix $T$ cell epitope recognized in human induces influenza protection in $\mathrm{HLA}-\mathrm{A} 2 / \mathrm{K}^{\mathrm{b}}$ transgenic mice. Virology. 2003:309:320-9.

36. Matsui M, Kohyama S, Suda T, Yokoyama S, Mori M, Kobayashi A, et al. A CTL-based liposomal vaccine capable of inducing protection against heterosubtypic influenza viruses in HLA-A*0201 transgenic mice. Biochem Biophys Res Commun. 2010;391:1494-9.

37. Kohlmeier JE, Woodland DL. Immunity to respiratory viruses. Annu Rev Immunol 2009;27:61-82

38. Takamura S, Roberts AD, Jelley Gibbs DM, Wittmer ST, Kohlmeier JE, Woodland DL. The route of priming influences the ability of respiratory virus-specific memory CD8+ T cells to be activated by residual antigen. J Exp Med. 2010;207:1153-60.

39. De Bree GJ, Van Leeuwen EM, Out TA, Jansen HM, Jonkers RE, Van Lier RA. Selective accumulation of differentiated CD8+ T cells specific for respiratory viruses in the human lung. J Exp Med. 2005;202:1433-42.

40. Purwar R, Campbell J, Murphy G, Richards WG, Clark RA, Kupper TS. Resident memory $T$ cells $(T(R M))$ are abundant in human lung: diversity, function, and antigen specificity. PLoS One. 2011;6:e16245.

41. Sallusto F, Geginat J, Lanzavecchia A. Central memory and effector memory T cell subsets: function, generation, and maintenance. Annu Rev Immunol. 2004;22:745-63.

42. Takada A, Matsushita S, Ninomiya A, Kawaoka Y, Kida H. Intranasal immunization with formalin-inactivated virus vaccine induces a broad spectrum of heterosubtypic immunity against influenza $A$ virus infection in mice. Vaccine. 2003;21:3212-8.

43. La Gruta NL, Rothwell WT, Cukalac T, Swan NG, Valkenburg SA, Kedzierska K, et al. Primary CTL response magnitude in mice is determined by the extent of naive $T$ cell recruitment and subsequent clonal expansion. J Clin Invest. 2010;120:1885-94.

44. Kurts C, Miller JF, Subramaniam RM, Carbone FR, Heath WR. Major Histocompatibility Complex class I-restricted cross-presentation is biased towards high dose antigens and those released during cellular destruction. J Exp Med. 1998;188:409-14.

45. Luciani F, Sanders MT, Oveissi S, Pang KC, Chen W. Increasing viral dose causes a reversal in CD8+ T cell immunodominance during primary influenza infection due to differences in antigen presentation, T cell avidity, and precursor numbers. J Immunol. 2013;190:36-47.

46. Tan AC, La Gruta NL, Zeng W, Jackson DC. Precursor frequency and competition dictate the HLA-A2-restricted CD8+ T cell responses to influenza A infection and vaccination in HLA-A2.1 transgenic mice. J Immunol. 2011;187:1895-902.

47. Pavelic V, Matter MS, Mumprecht S, Breyer I, Ochsenbein AF. CTL induction by cross-priming is restricted to immunodominant epitopes. Eur J Immunol. 2009:39:704-16.

48. Zammit DJ, Turner DL, Klonowski KD, Lefrancois L, Cauley LS. Residual antigen presentation after influenza virus infection affects CD8 T cell activation and migration. Immunity. 2006:24:439-49.

49. He XS, Holmes TH, Zhang C, Mahmood K, Kemble GW, et al. Cellular immune responses in children and adults receiving inactivated or live attenuated influenza vaccines. J Virol. 2006;80:11756-66.

50. Eichelberger MC, Rivers KH, Ream R, Gao J, Hassantoufighi A, Straight TM. Qualitative differences in T cell responses to live, attenuated and inactivated influenza vaccines. J Clin Cell Immunol. 2011:S4:002. doi:10.4172/2155-9899. S4-002.

51. Choo JA, Liu J, Toh X, Grotenbreg GM, Ren EC. The immunodominant influenza $A$ virus $\mathrm{M1}_{58-66}$ cytotoxic lymphocyte epitope exhibits degenerate class I major histocompatibility complex restriction in humans. J Virol. 2014; 88:10613-23.

52. Haanen JB, Wolkers MC, Kruisbeek AM, Schumacher TN. Selective expansion of cross-reactive CD8+ memory T cells by viral variants. J Exp Med. 1999; 190:1319-28.

53. Berkhoff EG, De Wit E, Geelhoed Mieras MM, Boon AC, Symons J, Fouchier RA, et al. Functional constraints of influenza A virus epitopes limit escape from cytotoxic T Iymphocytes. J Virol. 2005;79:11239-46.

54. Wahl A, McCoy W, Schafer F, Bardet W, Buchli R, Fremont DH, et al. T-cell tolerance for variability in an HLA class I-presented influenza A virus epitope. J Virol. 2009:83:9206-14.

55. Voeten JT, Bestebroer TM, Nieuwkoop NJ, Fouchier RA, Osterhaus AD, Rimmelzwaan GF. Antigenic drift in the influenza A virus (H3N2) 
nucleoprotein and escape from recognition by cytotoxic T lymphocytes. J Virol. 2000;74:6800-7.

56. Rimmelzwaan GF, Kreijtz JH, Bodewes R, Fouchier RA, Osterhaus AD. Influenza virus CTL epitopes, remarkably conserved and remarkably variable. Vaccine. 2009;27:6363-5.

57. Quinones Parra S, Grant E, Loh L, Nguyen TH, Campbell KA, Tong SY, et al. Preexisting CD8+ T-cell immunity to the H7N9 influenza virus varies across ethnicities. Proc Natl Acad Sci U S A. 2014;111:1049-54.

Submit your next manuscript to BioMed Central and we will help you at every step:

- We accept pre-submission inquiries

- Our selector tool helps you to find the most relevant journal

- We provide round the clock customer support

- Convenient online submission

- Thorough peer review

- Inclusion in PubMed and all major indexing services

- Maximum visibility for your research

Submit your manuscript at www.biomedcentral.com/submit 